\title{
Differential effects of selective PDE5 inhibitors in rat cerebral arteries in vitro and in vivo Christina Kruuse ${ }^{* 1,2,3}$, Saurabh Gupta ${ }^{2}$, Elisabet Nilsson ${ }^{4}$, Lars Kruse ${ }^{2}$ and Lars Edvinsson 4,5
}

\begin{abstract}
Address: ${ }^{1}$ Department of Neurology, Glostrup Hospital University of Copenhagen, Glostrup Denmark, ${ }^{2}$ Lundbeck Foundation Centre for Neurovascular Research, Glostrup Hospital, Glostrup Denmark, ${ }^{3}$ Dept. Clinical Biochemistry, Glostrup Research Park, Glostrup Hospital, Glostrup Denmark, ${ }^{4}$ Division of Experimental Vascular Research, Department of Internal Medicine, University Hospital of Lund, Lund, Sweden and ${ }^{5}$ Dept. Clinical Experimental Research, Glostrup Research Park, Glostrup Hospital, Denmark

Email: Christina Kruuse* - ckruuse@dadlnet.dk

* Corresponding author
\end{abstract}

from 4th International Conference of cGMP Generators, Effectors and Therapeutic Implications

Regensburg, Germany. 19-2I June 2009

Published: II August 2009

BMC Pharmacology 2009, 9(Suppl I):P38 doi:10.1186/147I-2210-9-SI-P38

This abstract is available from: http://www.biomedcentral.com//47I-22 I0/9/SI/P38

(c) 2009 Kruuse et al; licensee BioMed Central Ltd.

\section{Introduction}

Compounds which increase cGMP levels are implicated in migraine pathophysiology as well as stroke recovery. Inhibitors of the cGMP degrading enzyme phosphodiesterase type 5 (PDE5) induce headache and migraine in humans, however surprisingly and unlike other migraine inducing drugs without measurable dilatation of cerebral arteries [1] or changes in hemodynamic response or excitability [2]. We aimed to investigate whether sildenafil and tadalafil induced dilatation of rat middle cerebral and meningeal arteries in vitro and in vivo.

\section{Methods}

Dilatory responses of middle cerebral arteries from Sprague-Dawley rats were investigated using pressurised arteriograhy with application of the UK 114-542, sildenafil, tadalafil either intraluminally or extraluminally. Effects of i.v sildenafil and tadalafil on dural arteries in a closed cranial window in vivo rat model were investigated.

\section{Results}

Abluminal sildenafil induced dilatation only at concentrations above $0.1 \mu \mathrm{M}$ with a $\mathrm{pEC}_{50}$ of $6.74 \pm 0.86$ and $\mathrm{E}_{\max }$ of $36.3 \pm 8.3$. UK 114542 was slightly more potent with Emax $70.4 \pm 14.4 \%$ and $\mathrm{pEC}_{50}$ of $6.8 \pm 0.05(\mathrm{n}=4)$.
Abluminal application of tadalafil $(n=4)$ showed no dilatory effect compared to control. When applied luminally all PDE5 inhibitors elicited a slight contraction of approximately $10 \%$ at higher doses $(n=4)$.

Sildenafil dilated dural arteries at high doses in a dose dependent manner $(0.5$ to $3 \mathrm{mg} / \mathrm{kg})$, with $1 \mathrm{mg} / \mathrm{kg}$ producing $60 \pm 14 \%$ dilatation $(n=6)$. Tadalafil, however, failed to elicit significant dilatations in vivo.

\section{Discussion}

The selective PDE5 inhibitors tadalafil and sildenafil are poor vasodilators of intact cerebral arteries. Only at high concentrations where unspecific effects may prevail did they induce dilatation. In vivo, the rat dural artery may dilate at lower doses of the PDE5 inhibitors, than in vitro however still doses higher than the normal therapeutic level. In pain generation primary vascular effects of PDE5 inhibitors seems unrelated to migraine generation. Further, in intact cerebral arteries PDE5 inhibitor in clinical doses appear to mixed vascular effects at high doses.

\section{References}

I. Kruuse C, Thomsen LL, Birk S, Olesen J: Migraine can be induced by sildenafil without changes in middle cerebral artery diameter. Brain 2003, 126:24I-247. 
2. Kruuse $C$, Hansen AE, Larsson HB, Lauritzen M, Rostrup E: Cerebral haemodynamic response or excitability is not affected by sildenafil. J Cereb Blood Flow Metab 2009.

Publish with Bio Med Central and every scientist can read your work free of charge

"BioMed Central will be the most significant development for disseminating the results of biomedical research in our lifetime. " Sir Paul Nurse, Cancer Research UK

Your research papers will be:

- available free of charge to the entire biomedical community

- peer reviewed and published immediately upon acceptance

- cited in PubMed and archived on PubMed Central

- yours - you keep the copyright

Submit your manuscript here:

http://www.biomedcentral.com/info/publishing_adv.asp 